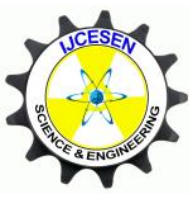

Copyright (C) IJCESEN
International Journal of Computational and

Experimental $\boldsymbol{S}$ cience and Engineering

(IJCESEN)

Vol. 5-No.3 (2019) pp. 147-150

http://dergipark.org.tr/ijcesen

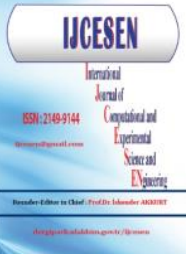

ISSN: 2149-9144

Research Article

\title{
Comparing the Effect of Process Fluid for Wet Ground Heat Exchanger
}

\author{
Ufuk DURMAZ*, Orhan YALÇINKAYA
}

Sakarya University/Mechanical Engineering Department, Sakarya -Turkey

* Corresponding Author : udurmaz@ sakarya.edu.tr ORCID: 0000-0001-5534-8117

\section{Article Info:}

DOI: $10.22399 /$ ijcesen.629842

Received : 06 October 2019

Accepted : 06 November 2019

\section{Keywords}

Ground Heat Exchangers

Energy Efficiency

Low Energy Buildings

\begin{abstract}
:
Nowadays, a considerable part of the energy need is covered by non-renewable energy sources such as coal, oil and natural gas. Although fossil fuels are formed in long periods, days they are consumed very rapidly, especially in these days. Therefore, the investigations on renewable energy sources, which can be used as an alternative to fossil fuels are increasing with each passing day. Recently, in order to increase heat transfer in the ground heat exchanger, the applications of moistening the soil are existing in the literature. In this research study, the effects of process fluid on heat transfer were investigated comparatively in a wet-soil source heat exchanger. The contribution to the thermal efficiency of air and water as a process fluid was examined. In this study, it is aimed to reduce energy costs. It has been determined that it will make a significant contribution to energy saving in energy-efficient smart buildings.
\end{abstract}

\section{Introduction}

There are many studies to find permanent solutions to the increasing energy problem. Today, usage of energy efficiently and development of renewable energy sources have become a necessity. The largest part of the energy requirement is covered by fossil fuels. The renewal times of fossil fuels are very long. Furthermore, using these fuels, lead to emission of harmful gases such as COx, NOx and SOx increase the greenhouse effect. In addition, these emissions cause a deterioration of ecological balance in terms of damaging the ozone layer. With increasing energy demand and consumption, researchers have focused on finding and developing renewable energy sources that are economic and environmentally friendly. Alternative energy sources like wet ground heat exchangers can be used for more economical and ecological heating-cooling processes. The current literature on ground heat exchangers should also be examined. Agrawal et. al. [1] developed a laboratory scale experimental set up for ground-air heat exchanger (GAHE) system. They provided a certain level of moisture into the soil in the close vicinity of GAHE pipe and evaluate the effect of sand-bentonite backfilling material (dry as well as wet) on performance of GAHE system and evaluated the effect of sand-bentonite backfilling material (dry as well as wet) on performance of GAHE system. Agrawall et al. [2] determined that by increasing air flow velocity $2 \mathrm{~m} / \mathrm{s}$ to $10 \mathrm{~m} / \mathrm{s}$, cooling capacity increases $220 \%$ in wet soil and also found that the required length of GAHE pipe depends on soil moisture, air velocity and pipe diameter. Lin et al. [3] assessed long-term performance of a full-scale EAHE and characterized at different moisture contents of soil thermal properties. They simulated the system for a period of 3 years with an analytical solution. Cunny et al. [4] presented an experimental study of the soil moisture content's variation under defined rains. They concluded that EAHE's energy gain after a rain event is over $4 \%$ for the first $24 \mathrm{~h}$ and determined that cumulated precipitation influences more than rain density on energy increasing. Misra et al. [5] evaluated thermal performance of the earth air tunnel heat exchanger (EATHE) system with dry and wet soil. They compared thermal behavior of dry soil EATHE system with that of wet soil EATHE system on the basis of air temperature along the length of pipe and carried out a parametric study to optimize the soil moisture content for wet EATHE system. Belatrache 
et al. [6] modeled and simulated an EAHE under hot arid climate conditions of the south of Algeria. They evaluated energy saving by using EAHE's for air conditioning applications in arid climatic conditions and also evaluated effect of geometric parameters and operating conditions on the thermal performance of EAHE's. Guohui Gan [7] developed a methodology to generate soil moisture and temperature profiles. With this methodology, remarkable impact of soil moisture on thermal performance of ground heat exchanger was determined. Hu Li et al. [8] examined characteristics of heat and moisture transfer at various temperature levels. Some results of their studies; for dry soil at steady-state conditions highest temperature deviation is $18.6 \%$ and for wet soil at steady-state conditions highest temperature deviation is $7.7 \%$. Papakostas et al. [9] compared two one-dimensional models of earth-to-air heat exchangers and then compared and validated theoretical results with experimental data. The results were similar with those found through CFD simulation. Their results presented a deviation of less than $10 \%$ compared to measurements. Habibi and Hakkaki-Fard [10] numerically evaluated thermal performance of horizontal ground heat exchangers. They compared initial installation cost of different types of horizontal GHEs. They concluded that moistening the secondary soil can reduce the GHE installation cost up to $40 \%$. Soil can be considered a heat sink to reduce the costs of cooling during the summer months. Recently, there has been a rapidly increasing number of studies in the literature aimed at increasing the moisture content of the soil around the pipe system of ground source heat exchangers (GHE). In this way, heat transfer also increases significantly as a result of increasing soil moisture [5]. The aim of this study is to compare the effect of water and air as a process fluid on the heat transfer in a wet soil heat exchanger used for cooling. For this purpose, a wet ground heat exchanger (WGHE) was used to cool a test room in the campus of Sakarya University during summer months [11,12]. In this system, where air or water is used as process fluid, the inlet and outlet temperatures of the ground source heat exchanger were determined separately for both fluids in July and August and the heat energy transferred to the soil per unit time was calculated.

\section{Materials and Method}

The main reason to use the soil as a heat source or a heat sink is staying stable its temperature throughout the year. The distance between the pipes of the heat exchanger is 0.3 meters [13] in the system used for

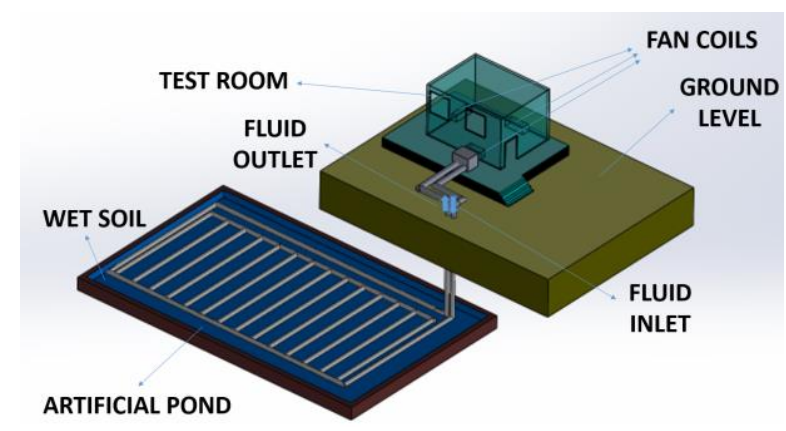

Figure 1. Artificial pond-based cooling system with wet ground source heat exchanger.

cooling by taking advantage of constant soil temperature. Polypropylene pipes with a diameter of $70 \mathrm{~mm}$ were used for water as process fluid, while the pipes with a diameter of $100 \mathrm{~mm}$ were used in experiments for air. In experiments with air, the inlet of the wet ground source heat exchanger is the air of the test room. The outlet of the heat exchanger is the cold air below the soil and it is sent directly to the test room for air-conditioning. In experiments with water, the inlet of the wet ground source heat exchanger is the water that is passed through from the fan coils in the test room. The output of the heat exchanger is the water which was cooled under the ground.

The heat transfer between the process fluid and the air of the test room is calculated with the following equation.

$$
\dot{Q}=\dot{m} \cdot c_{p} \cdot \Delta T
$$

Here, $\dot{Q}$ is the heat transfer rate in $\mathrm{kW}$ and it is directly dependent on temperature difference and mass flow rate. The $\dot{m}$ is mass flow rate in $\mathrm{kg} / \mathrm{s}, c_{p}$ is specific heat in $\mathrm{kJ} / \mathrm{kg}^{\circ} \mathrm{C}$ and $\mathrm{T}$ is the temperature in ${ }^{\circ} \mathrm{C}$. Heat transfer rates were calculated for both fluids using the aforementioned equation above and compared according to months.

\section{Experimental Results and Discussions}

In experiments with process fluid air, ambient air is sent to the WGHE system with the help of a fan to obtain chilled air at the exit of the system. In measurements where the fluid is water, low and constant soil temperature has been utilized by the WGHE system. A pump circulates the cooled water and the test room is cooled by sending it to fan coils. In the experiments conducted in July and August, temperature changes of air and water fluids entering the WGHE can be observed in Figure 2. The values in figures are data for the average of daily measurements in those months. The reason that the inlet temperature of the water fluid is lower than that 


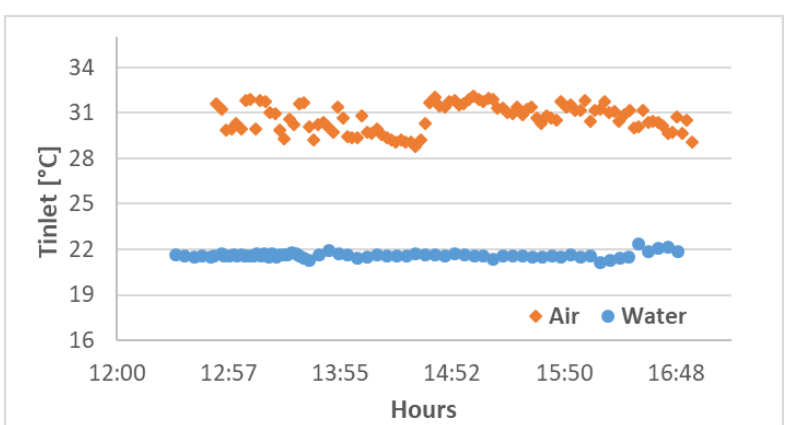

Figure 2. The WGHE inlet average temperatures of the process fluids in July and August.

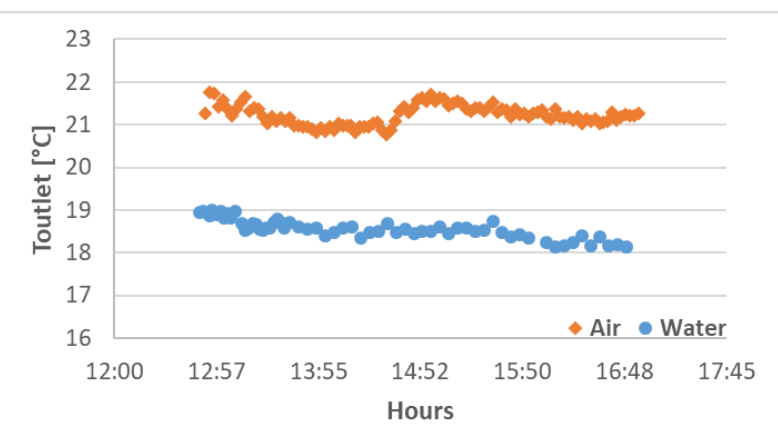

Figure 3. The WGHE outlet average temperatures of the process fluids in July and August.

of the air fluid is due to the fact that the temperature of the mains water is at an average of $20^{\circ} \mathrm{C}$. The inlet temperature of the air exhibits small fluctuations around $31{ }^{\circ} \mathrm{C}$, whereas the inlet temperature of the water fluid remains almost constant at $22^{\circ} \mathrm{C}$ (Figure 2). Figure 3 shows the outlet temperatures of the process fluids from the system. It is seen that the outlet temperature of the air fluid remains nearly constant around an average of $21{ }^{\circ} \mathrm{C}$ and the temperature of the water fluid decreases from $19^{\circ} \mathrm{C}$ to $18^{\circ} \mathrm{C}$. It is estimated that local losses in the piping and the heat transfer in the fins of the thermocouple used during the measurements cause the temperature of the water fluid to decrease by $1{ }^{\circ} \mathrm{C}$. Because the soil can be considered as a heat sink, the change in temperature is almost negligible. The reason that the outlet temperatures do not change much for both fluids is that the wet soil acts as like a heat sink. When these experimental results are analyzed, it is understood that the piping and artificial pond systems established in an area of $80 \mathrm{~m}^{2}$ in the previous study are sufficient. Figure 4 shows the average temperature differences of water and air fluids. A high temperature difference means that the heat energy transferred to the soil increases. The reason for the higher temperature difference results from that the losses in the system are minimal and the heat is transferred directly to the soil when air fluid is used in the WGHE system. In the experiments carried out with water, the local losses caused by the failure of the mains water to contact

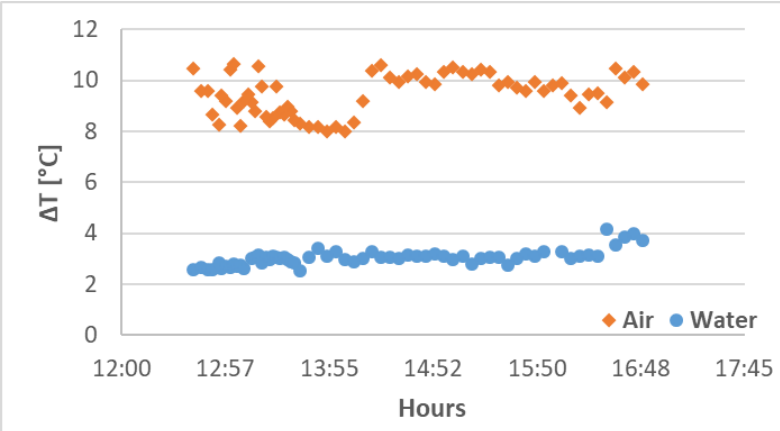

Figure 4. Average temperature differences of the process fluids in July and August.

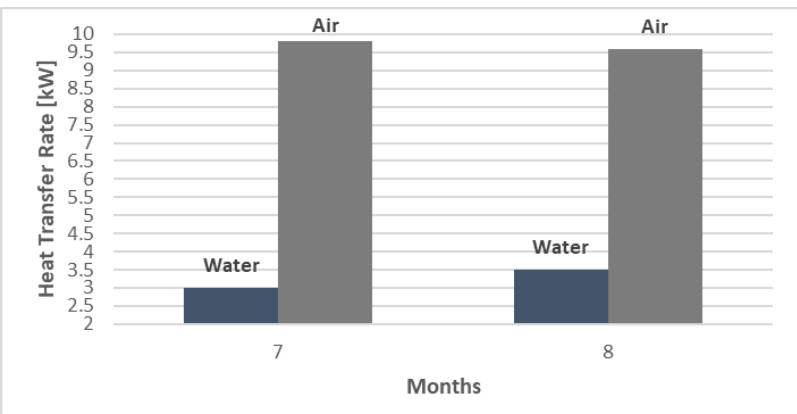

Figure 5. Heat transfer rates for the process fluids in July and August.

all the pipes of the system and the dry areas remained, have reduced the efficiency considerably. Figure 5 comparatively presents the average heat energy sent to the heat sink in July (7) and August (8). When air is preferred as the process fluid, an average of 9-10 kW heat energy is transferred to the soil per unit time but when water fluid is used, average $3-3.5 \mathrm{~kW}$ is transferred to the test room.

\section{Conclusions}

In the experiments carried out in July and August, average $9-10 \mathrm{~kW}$ heat energy was transferred to the soil with air fluid per unit time.in Sakarya, Turkey. In this way, it has been seen that cooling costs can be reduced. In experiments with air fluid, more heat energy was transferred to soil than water. This is due to the use of air in direct cooling. In the experiments where the water fluid was used, the efficiency decreased as it was not used directly for cooling as in the air experiments. In other words, the presence of a second heat transfer mechanism between the air and the water in the environment where air conditioning is performed has caused the efficiency to decrease. In addition, the heat energy transferred to the test room with the water fluid per unit time remained around $3.5 \mathrm{~kW}$, since full waterproofing was not achieved. In this system, which is examined as a closed loop system, it is obvious that if the water is used from natural underground sources such as 
water-wells, the efficiency of the water fluid will increase significantly. Considering the results obtained for both process fluid, it is seen that integrating this system with other alternative systems will provide much more efficient solutions, especially in summer months. Thus, the system could be contributed significantly to the energy efficiency of the low-energy buildings.

\section{Acknowledgement}

This work was supported by Research Fund of the Sakarya University. Project Number: 2015-01-06002.

\section{References}

[1] K.K. Agrawal, R. Misra, G. Das Agrawal, "Improving the thermal performance of ground air heat exchanger system using sand-bentonite (in dry and wet condition) as backfilling material", Renew. Energy. 146 (2020) 2008-2023. doi:10.1016/j.renene.2019.08.044.

[2] K.K. Agrawal, R. Misra, G. Das Agrawal, "To study the effect of different parameters on the thermal performance of ground-air heat exchanger system: In situ measurement", Renew. Energy. 146 (2020) 20702083. doi:10.1016/j.renene.2019.08.065.

[3] J. Lin, H. Nowamooz, S. Braymand, P. Wolff, C. Fond, "Impact of soil moisture on the long-term energy performance of an earth-air heat exchanger system", Renew. Energy. (2018) 1-12. doi:10.1016/j.renene.2018.06.106.

[4] M. Cuny, J. Lin, M. Siroux, C. Fond, "Influence of rainfall events on the energy performance of an earthair heat exchanger embedded in a multilayered soil", Renew. Energy. (2019) 1-12. doi:10.1016/j.renene.2019.01.071.

[5] R. Misra, S. Jakhar, K.K. Agrawal, S. Sharma, D.K. Jamuwa, M.S. Soni, G. Das Agrawal, "Field investigations to determine the thermal performance of earth air tunnel heat exchanger with dry and wet soil: Energy and exergetic analysis", Energy Build. 171 (2018) 107-115. doi:10.1016/j.enbuild.2018.04.026.

[6] D. Belatrache, S. Bentouba, M. Bourouis, "Numerical analysis of earth air heat exchangers at operating conditions in arid climates", Int. J. Hydrogen Energy. 42 (2017) 8898-8904. doi:10.1016/j.ijhydene.2016.08.221.

[7] G. Gan, "A numerical methodology for comprehensive assessment of the dynamic thermal performance of horizontal ground heat exchangers", Therm. Sci. Eng. Prog. 11 (2019) 365-379. doi:10.1016/j.tsep.2019.04.013.

[8] H. Li, L. Ni, Y. Yao, C. Sun, "Experimental investigation on the cooling performance of an Earth to Air Heat Exchanger (EAHE) equipped with an irrigation system to adjust soil moisture", Energy Build. $196 \quad$ (2019) 280-292. doi:10.1016/j.enbuild.2019.05.007.
[9] K.T. Papakostas, A. Tsamitros, G. Martinopoulos, "Validation of modified one-dimensional models simulating the thermal behavior of earth-to-air heat exchangers - Comparative analysis of modelling and experimental results", Geothermics. 82 (2019) 1-6. doi:10.1016/j.geothermics.2019.05.013.

[10] M. Habibi, A. Hakkaki-Fard, "Evaluation and improvement of the thermal performance of different types of horizontal ground heat exchangers based on techno-economic analysis", Energy Convers. Manag. 171 (2018) 1177-1192. doi:10.1016/j.enconman.2018.06.070.

[11] U. Durmaz, M. Ozdemir, "An experimental study on the soil-based natural cooling", Int. J. Environ. Sci. Technol. 16 (2019) 1-4. doi:10.1007/s13762-0181691-1.

[12] U. Durmaz, O. Yalçınkaya, "Experimental investigation on the ground heat exchanger with air fluid", Int. J. Environ. Sci. Technol. (2019) 1-6. doi:10.1007/s13762-019-02205-w.

[13] Y. Nam, H.-B. Chae, "Numerical simulation for the optimum design of ground source heat pump system using building foundation as horizontal heat exchanger", Energy. 73 (2014) 933-942. doi:10.1016/j.energy.2014.06.108. 